УДК 615.322: 616.1-085

\title{
ОСОБЕННОСТИ НАКОПЛЕНИЯ МАКРО- И МИКРОЭЛЕМЕНТОВ В НАДЗЕМНОЙ ЧАСТИ FILIPENDULA ULMARIA (L) MAXIM В РАЗНЫЕ ФЕНОЛОГИЧЕСКИЕ ФАЗЫ
}

\author{
() И.Д. Зыкова, А.А. Ерремов", В.С. Герасимов, А.А. Лешок \\ Сибирский феедеральный университет, пр. Свободный, 79, Красноярск, \\ 660075 (Россия), e-mail: izykova@sfu-kras.ru
}

Методом атомно-эмиссионного анализа исследован элементный состав надземной части Filipendula Ulmaria $(L)$ Maxim в зависимости от фазы развития растения. Определено количественное содержание 15 макро- и микроэлементов. Отмечено высокое содержание железа в фазе вегетации, кремния - в фазе цветения и стронция - в фазе плодоношения. Установлено, что по содержанию технофильных элементов надземная часть растения не превышает ПДК, принятых для чая и напитков.

Ключевые слова: лабазник вязолистный, фенологические фазы, элементный состав, атомно-эмиссионный анализ.

\section{Введение}

Известно, что физиологическое действие растительных препаратов на организм обусловлено не только биологически активными соединениями растений. Растительные объекты являются перспективными источниками различных макро- и микроэлементов и поэтому могут использоваться в качестве профилактических и лечебных средств в комплексной терапии микроэлементозов [1, 2]. Поэтому информация о содержании элементов в растениях и соотношениях между ними является крайне важной для принятия решения о целесообразности их применения в медицинской практике.

Filipendula Ulmaria (L) Maxim семейства Rosaceae (лабазник вязолистный) - лекарственное растение, издавна применяющееся в народной медицине благодаря наличию в нем разнообразных фармакологических веществ органической природы [3-5]. Широко распространено на территории Восточной Сибири и Красноярского края [6].

Сведения о содержании химических элементов в лабазнике вязолистном, произрастающем на территории Красноярского края, ограничены. В доступной научной литературе имеются данные о распределении макроэлементов в растениях этого рода в Курской области [7], в Северном Алтае [8]. В указанных работах приводятся результаты исследования элементного состава надземной части лабазника вязолистного в фазе

\footnotetext{
Зыкова Ирина Деменьтьевна - доцент кафедры химии, кандидат технических наук, e-mail: izykova@sfu-kras.ru Ефремов Александр Алексеевич - заведующий лабораторией хроматографических методов анализа центра коллективного пользования, доктор химических наук, профессор, e-mail: AEfremov@sfu-kras.ru Лешок Александр Александрович - заведующий лабораторией атомно-эмиссионных методов анализа, кандидат химических наук

Герасимов Валерий Сергеевич - заведующий лабораторией молекулярно-спектроскопических методов анализа, кандидат физико-математических наук
} цветения. Однако известно, что содержание макро- и микроэлементов в растениях варьирует в широких пределах в зависимости от анализируемого органа, фазы развития растения и при изменении ландшафтногеохимических условий их произрастания [9].

В связи с этим цель работы состояла в изучении особенностей накопления макро- и микроэлементов в надземной части лабазника вязолистного, произрастающего в окрестностях Красноярска, в различные фазы развития растения.

\footnotetext{
* Автор, с которым следует вести переписку.
} 


\section{Материалы и методы}

Сбор исследуемого материала (надземной части $F$. ulmaria) осуществляли в окрестностях Красноярска вдали от селитебных территорий в различные фенологические фазы развития растения, а именно: вегетации, включающей формирование розеток из листьев и рост стебля, бутонизации, цветения и плодоношения. Сырье сушили до воздушно-сухого состояния.

Визуальных признаков токсического влияния на растение избыточных количеств каких-либо элементов, содержащихся как в почве, так и в атмосфере, отмечено не было. Для анализа отбирали как отдельные экземпляры растений, так и средние пробы с определенной единицы площади в местах массового произрастания. Очищенные от минеральной пыли надземные органы измельчали и методом квартования брали пробы для элементного анализа.

Определение зольности разных частей растения проводили в трех параллельных пробах путем озоления измельченных образцов в муфельной печи при температуре 500-600 ${ }^{\circ} \mathrm{C}$ при доступе воздуха до полного озоления. Полученную золу после охлаждения взвешивали на аналитических весах. Зольность надземной части, собранной в фазу вегетации, составила $8,4 \pm 0,2 \%$, в фазу бутонизации $-5,8 \pm 0,1 \%$, в фазы

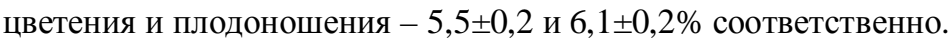

Количественный состав и качественное содержание минеральных элементов определяли с использованием атомно-эмиссионного спектрометра Thermo Scientific iCAP-6500 DUO и программного пакета iTEVA. Данное оборудование и программное обеспечение предназначено для проведения количественного элементного анализа. Спектрометр оборудован системой двойного обзора плазмы (аксиального и радиального), что позволяет определять элементы как в высокой, так и в низкой концентрации. Исследуемые спектральные линии элементов выбирались так, чтобы они не накладывались на линии других элементов, присутствующих в образцах, что может привести к завышению реальных значений концентрации. Итоговая концентрация элементов определялась сравнением интенсивности аналитического сигнала образца с интенсивностью сигнала калибровочного стандарта на длине волны соответствующей выбранной линии.

\section{Результаты и обсуждение}

В надземной части $F$. ulmaria определено количественное содержание 15 макро- и микроэлементов (табл.), а также выявлены некоторые закономерности в распределении этих элементов в течение всего периода вегетации.

При сравнительном анализе исследуемых образцов наряду с идентичностью их качественного состава отмечено варьирование в содержании отдельных жизненно важных и токсичных элементов в зависимости от фазы развития растения.

Согласно данным, приведенным в таблице, количественное содержание бора в надземной части $F$. ulmaria увеличивается по мере развития растения, достигая максимума (43,0 мг/кг) в фазе плодоношения. Количество кальция варьирует в пределах от 6,4 мг/кг в фазе цветения до 16,1 мг/кг в фазе плодоношения. Барий интенсивно накапливается в фазе цветения растения. В достаточных количествах $F$. ulmaria аккумулирует медь и цинк, что объясняется их важной биохимической функцией [1]. Согласно литературным данным, нормальная концентрация меди в растениях находится на уровне 0,2-20,0 мг/кг, цинка - 15-150 мг/кг, предположительно максимальное - 300 мг/кг воздушно-сухой массы [10]. Для данных металлов обнаружена одинаковая тенденция накопления в течение всего периода развития растения. Наиболышее содержание меди (23,0 мг/кг) и цинка (52,0 мг/кг) отмечено в фазе вегетации. Исходя из приведенных норм можно отметить, что концентрации меди и цинка в образцах $F$. ulmaria укладываются в диапазон нормального функционирования растения.

Содержание марганца рассматривали во взаимосвязи с содержанием железа, поскольку марганец и железо являются элементами-антагонистами [11]. Величина Fe/Mn имеет решающее значение при оценке устойчивости растений к железистой токсичности. Для нормального развития растений это соотношение должно быть в пределах 1,5-2,5 [12]. Соотношение элементов Fe/Mn для исследуемых образцов не сильно отклоняется от нормы в фазе плодоношения и составляет 2,8, в фазе бутонизации соотношение Fe/Mn ниже нормы и составляет 1,0; в фазе вегетации и цветения - выше нормы (3,4 и 4,2 соответственно). Максимальная концентрация железа (158,0 мг/кг) отмечена в фазе вегетации, а максимальная концентрация марганца (51,0 мг/кг) - в фазе плодоношения.

Содержание никеля широко варьирует в зависимости от стадии развития растения, достигая максимума в фазе бугонизации. 
Таблица 1. Содержание элементов в надземной части F. Ulmaria (в мг/ кг абс. сух. растения) в разные фенофазы

\begin{tabular}{c|c|c|c|c}
\hline \multirow{2}{*}{ Элемент } & \multicolumn{4}{|c}{ Фенологическая фаза } \\
\cline { 2 - 5 } & вегетации & бутонизации & цветения & плодоношения \\
\hline $\mathrm{B}$ & $25,0^{*}$ & 25,0 & 31,0 & 43,0 \\
$\mathrm{Ba}$ & 25,0 & 13,3 & 36,0 & 12,0 \\
$\mathrm{Ca}$ & 6,8 & 7,1 & 6,4 & 16,1 \\
$\mathrm{Cu}$ & 23,0 & 22,0 & 10,2 & 0,040 \\
$\mathrm{Cd}$ & 0,038 & 0,008 & 0,042 & 144,0 \\
$\mathrm{Fe}$ & 158,0 & 146,0 & 63,0 & 51,0 \\
$\mathrm{Mn}$ & 37,0 & 145,0 & 18,1 & 6,1 \\
$\mathrm{Ni}$ & 5,4 & 8,2 & 2,4 & 0,01 \\
$\mathrm{Sb}$ & $<0,007$ & 380,0 & 0,04 & 0,023 \\
$\mathrm{Si}$ & 66,0 & 0,008 & 503,0 & 72,0 \\
$\mathrm{Sn}$ & $<0,007$ & 22,0 & 0,01 & 0,02 \\
$\mathrm{Sr}$ & 47,0 & 0,02 & 33,0 & 6,5 \\
$\mathrm{Se}$ & 0,01 & 7,7 & 0,02 & 38,0 \\
$\mathrm{Ti}$ & 13,1 & 38,0 & 3,2 & 19,3 \\
$\mathrm{Zn}$ & 52,0 &
\end{tabular}

Примечание. сууммарная погрешность составляет не более $5 \%$ от определяемой величины.

Нормальное содержание кадмия в растениях - 0,05-0,2 мг/кг воздушно-сухой массы, предположительно максимальное - 3 мг/кг [10]. Несмотря на то, что кадмий имеет для растений физиологическое значение, этот микроэлемент относят к технофильным элементам, поскольку его концентрация в растениях может увеличиваться за счет техногенного воздействия. Поступление в растение повышенного количества этого элемента довольно часто вызывает ряд физиологических и морфологических изменений. По нашим данным, концентрация кадмия в исследуемых образцах составляет 0,008-0,04 мг/кг, что соответствует ПДК, принятым для чая и напитков [13].

Сурьма не считается жизненно необходимым металлом, но известно, что ее растворимые формы активно извлекаются растениями из почв. И даже при низких концентрациях сурьма представляет опасность [14]. Среднее содержание ее в наземных органах оценивается в 0,06 мг/кг сухой массы. В исследуемых нами образцах максимальная концентрация сурьмы $(0,04$ мг/кг) отмечена в фазу вегетации.

Титан - сильный восстановитель, поэтому предполагают, что он играет определенную роль в фотоситезе, а может быть, и в фиксации молекулярного азота. Однако отсутствуют доказательства того, что титан является незаменимым для растений элементом [15]. В надземной части $F$. ulmaria максимальная концентрация титана отмечена в фазе вегетации (13,1 мг/кг).

Изучению распределения селена $(\mathrm{Se})$ в растениях посвящены многочисленные исследования, однако физиологическая роль $\mathrm{Se}$ все еще не известна. Существует мнение, что он может вовлекаться в определенные метаболические процессы, особенно в растениях, активно его концентрирующих [16], но необходимость этого элемента для развития растений однозначно не установлена. Среднее содержание данного элемента в растениях составляет 0,1 мг/кг. В лабазнике вязолистном «следовое» содержание селена в зависимости от фенофазы варьирует в интервале $0,01-0,02$ мг/кг.

Согласно литературным данным, многие лекарственные растения, обогащенные флавоноидами, одновременно являются и кремнефильными растениями [17]. Лабазник вязолистный не является здесь исключением. Большое количество кремния приходится на фазу цветения растения (503,0 мг/кг). Высокое содержание стронция ( $\mathrm{Sr}$ ) отмечено в фазе плодоношения. Это может быть связано с высокой подвижностью ${ }^{90} \mathrm{Sr}$ и быстрым поглощением его растением [18].

Таким образом, лабазник вязолистный характеризуется различным содержанием макро- и микроэлементов в разных стадиях фенологического развития. Установлено, что по содержанию технофильных элементов надземная часть растения не превышает ПДК, принятых для чая и напитков. Элементный химический состав лабазника вязолистного, произрастающего в окрестностях Красноярска, можно рассматривать как отражение биогеохимической ситуации экологически чистого региона с ненарушенными естественными биогеохимическими циклами элементов.

\section{Сиисок литературы}

1. Ловкова М.Я., Рабинович А.М., Пономарева С.М. Почему растения лечат. М., 1989. 256 с.

2. Львов С.Н., Хорунжий В.В., Земляной Д.А., Александрович И.В., Горбачев В.И., Пшениснов К.В. Особенности микроэлементного статуса у школьников // Сибирский медицинский журнал. 2011. №6. С. 68-71. 
3. Шанцер И.А. Лабазники. М., 2001. 32 с.

4. Растения в медицине / под ред. Б.Р. Волынского. Саратов, 1989. 517 с.

5. Махлаюк В.П. Лекарственные растения в народной медицине. М., 1992. 136 с.

6. Махов А.А. Зеленая аптека. Красноярск, 1993. 528 с.

7. Бубенчикова В.Н., Сухомлинов Ю.А. Минеральный состав растений рода Лабазник // Вестник ВГУ. Серия: Химия. Биология. Фармация. 2006. №1. С. 189-190.

8. Мешкинова С.С., Ельчининова О.А., Шаховцева Е.В. Микроэлементы в растениях Северного Алтая // Ползуновский вестник. 2006. №2. С. 291-295.

9. Алексеенко В.А. Основные факторы накопления химических элементов организмами // Соросовский образовательный журнал. 2001. Т. 7, №8. С. 20-24.

10. Ильин В.Б., Юданова Л.А. Тяжелые металлы в почвах и растениях // Поведение ртути и других металлов в экосистемах. Ч. ІІ. Процессы биоаккумуляции и экотоксикология. Новосибирск, 1989. С. 6-47.

11. Школьник М.Я. Микроэлементы в жизни растений. Л., 1974. 324 с.

12. Кабата-Пендиас А., Пендиас Х. Микроэлементы в почвах и растениях. М., 1989. 439 с.

13. Санитарные правила и нормы 2.3.2.1078-01. Гигиенические требования к безопасности и пищевой ценности пищевых продуктов. Продовольственное сырье и пищевые продукты. М., 2002.

14. Алексеев Ю.В. Тяжелые металлы в почвах и растениях. Л., 1987. 142 с.

15. Исаев Ю.А. Лечение микроэлементами, металлами и минералами. Киев, 1992. 326 с.

16. Ермаков В.В., Ковальский В.В. Биологическое значение селена. М., 1974. 300 с.

17. Колесников М.П. Формы кремния в растениях // Успехи биологической химии. 2001. Т. 41. С. 301-332.

18. Тихомиров Ф.А., Санжарова Н.И., Смирнов Е.Г. Накопление ${ }^{90} \mathrm{Sr}$ травянистыми растениями луга и леса // Лесоведение. 1976. №5. С. 78-84.

Поступило в редакичию 3 марта 2012 г.

Zykova I.D., Efremov A.A., Gerasimov V.S., Leshok A.A. FEATURES OF THE ACCUMULATION OF MACROAND MICRONUTRIENTS IN THE ABOVEGROUND PARTS FILIPENDULA ULMARIA (L) MAHIM IN DIFFERENT PHENOLOGICAL PHASES

Siberian Federal University, st. Svobodnyi, 79, Krasnoyarsk, 660041 (Russia),e-mail: AEfremov@sfu-kras.ru

By atomic-emission analysis the elemental composition of aboveground parts of Filipendula Ulmaria (L) Mahim, depending on the phase of plant development was investigated. The quantitative content of 15 macro- and microelements. The high content of iron in the phase of vegetation, silicon - in flowering stage and strontium - in the fruiting phase was noted. Found that the content of tehnofilnyh elements of aboveground part of the plant does not exceed the MPC adopted for tea and drinks.

Keywoods: Filipendula Ulmaria (L) Maxim, phenological phases, elemental composition, atomic-emission analysis.

\section{References}

1. Lovkova M.Ia., Rabinovich A.M., Ponomareva S.M. Pochemu rasteniia lechat. [Why plants are treated]. Moscow, 1989, 256 p. (in Russ.).

2. L'vov S.N., Khorunzhii V.V., Zemlianoi D.A., Aleksandrovich I.V., Gorbachev V.I., Pshenisnov K.V. Sibirskii meditsinskii zhurnal, 2011, no. 6, pp. 68-71. (in Russ.).

3. Shantser I.A. Labazniki. [Meadowsweet]. Moscow, 2001, 32 p. (in Russ.).

4. Rasteniia $v$ meditsine / pod red. B.R. Volynskogo. [Plants in medicine. Ed. B.R. Volyn]. Saratov, 1989, 517 p. (in Russ.).

5. Makhlaiuk V.P. Lekarstvennye rasteniia v narodnoi meditsine. [Medicinal plants in folk medicine.]. Moscow, 1992, 136 p. (in Russ.).

6. Makhov A.A. Zelenaia apteka. [Green Pharmacy]. Krasnoyarsk, 1993, 528 p. (in Russ.).

7. Bubenchikova V.N., Sukhomlinov Iu.A. Vestnik VGU. Seriia: Khimiia. Biologiia. Farmatsiia, 2006, no. 1, pp. $189-190$. (in Russ.).

8. Meshkinova S.S., El'chininova O.A., Shakhovtseva E.V. Polzunovskii vestnik, 2006, no. 2, pp. 291-295. (in Russ.).

9. Alekseenko V.A. Sorosovskii obrazovatel'nyi zhurnal, 2001, vol. 7, no. 8, pp. 20-24. (in Russ.).

\footnotetext{
* Corresponding author.
} 
10. Il'in V.B., Iudanova L.A. Povedenie rtuti i drugikh metallov v ekosistemakh. Chast' II. Protsessy bioakkumu-liatsii $i$ ekotoksikologiia. [The behavior of mercury and other metals in ecosystems. Part II. Bioaccumulation and ecotoxicology]. Novosibirsk, 1989, pp. 6-47. (in Russ.).

11. Shkol'nik M.Ia. Mikroelementy $v$ zhizni rastenii. [Trace elements in the life of plants]. Leningrad, 1974, 324 p. (in Russ.).

12. Kabata-Pendias A., Pendias Kh. Mikroelementy $v$ pochvakh i rasteniiakh. [Trace elements in soils and plants]. Moscow, 1989, 439 p. (in Russ.).

13. Sanitarnye pravila $i$ normy 2.3.2.1078-01. Gigienicheskie trebovaniia $k$ bezopasnosti $i$ pishchevoi tsennosti pishchevykh produktov. Prodovol'stvennoe syr'e i pishchevye produkty. [Sanitary rules and norms 2.3.2.1078-01. Hygiene requirements for the safety and nutritional value of foods. Food raw materials and food products]. Moscow, 2002. (in Russ.).

14. Alekseev Iu.V. Tiazhelye metally v pochvakh i rasteniiakh. [Heavy metals in soils and plants]. Leningrad, 1987, 142 p. (in Russ.).

15. Isaev Iu.A. Lechenie mikroelementami, metallami i mineralami. [Treatment of trace elements, metals and minerals]. Kiev, 1992, 326 p. (in Russ.).

16. Ermakov V.V., Koval'skii V.V. Biologicheskoe znachenie selena. [The biological significance of selenium]. Moscow, 1974, 300 p. (in Russ.).

17. Kolesnikov M.P. Uspekhi biologicheskoi khimii, 2001, vol. 41, pp. 301-332. (in Russ.).

18. Tikhomirov F.A., Sanzharova N.I., Smirnov E.G. Lesovedenie, 1976, no. 5, pp. 78-84. (in Russ.).

Received March 3, 2012 
